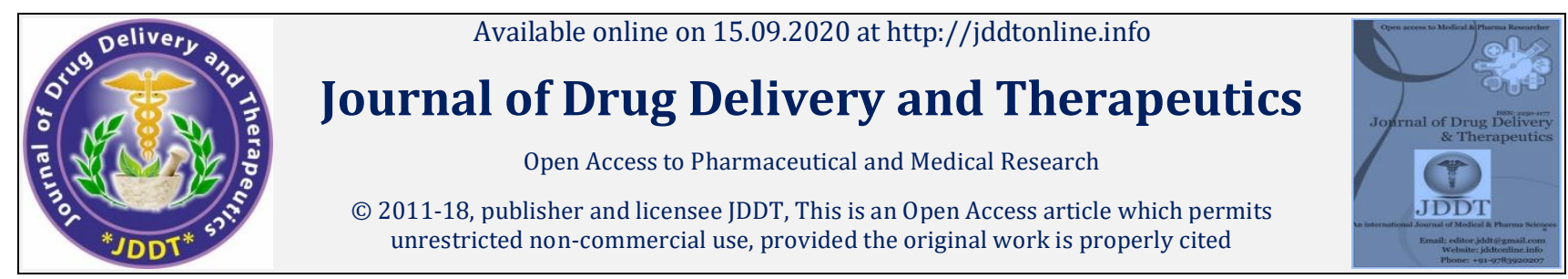

Open $\odot$ Access

Review Article

\title{
Concept of process capability indices as a tool for process performance measures and its pharmaceutical application
}

\author{
Abikesh Prasada Kumar Mahapatra*11, Jianwu Song1' Zhibo Shao², Tang Dong'2, Zihong Gong'2, Basudev Paul ${ }^{3}$, \\ Indira Padhy ${ }^{4}$ \\ 1,2 Shandong Maichuang Biopharmaceutical Co. Ltd., No. 1 Lutai Ave, Zibo City, Shangdong, CHINA \\ ${ }^{3}$ Shanghai Jingfeng Pharmaceutical Co. Ltd., Baoshan, Shanghai, CHINA \\ ${ }^{4}$ Khallikote Autonomous College, Berhampur, Ganjam, Odisha-760001, INDIA
}

\begin{abstract}
The main objective of the present study is to present the concept of process capability and to focus its significance in phar maceutical industries. From a practical view point, the control charts (such as X and R hart) sometimes are not convenient summary statistics when hundreds of characteristics in a plant or supply base are considered. In many situations, capability indices can be used to relate the process parameters. The resulting indices are unit less and provide a common, easily understood language for quantifying the performance of a process. Process capability indices (PCIs) are powerful means of studying the process ability for manufacturing a product that meets specifications. Several capability indices including $C p, C p u, C p l$ and $C p k$ have been widely used in manufacturing industry to provide common quantitative measures on process potential and performance. The formulas for these indices are easily understood and can be directly implemented. A process capability analysis compares the distribution of output from an in-control process to its specifications limits to determine the consistency with which the specifications can be met. The process capability is also having a significant role in pharmaceutical industry. Process capability indices can be a powerful tool by which to ensure drug product quality and process robustness. Determining process capability provides far more insight into any pharmaceutical process performance than simply computing the percentage of batches that pass or fail each year.
\end{abstract}

Keywords: Process capability; Cp/Cpk; Pp/Ppk; Pharmaceutical quality, process robustness, specification

Article Info: Received 08 July 2020; Review Completed 19 August 2020; Accepted 26 August 2020; Available online 15 Sep 2020

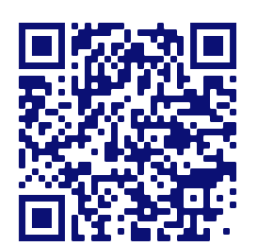

Cite this article as:

Mahapatra APK, Song J, Shao Z, Dong T, Gong Z, Paul B, Padhy I, Concept of process capability indices as a tool for process performance measures and its pharmaceutical application, Journal of Drug Delivery and Therapeutics. 2020; 10(5):333344 http://dx.doi.org/10.22270/jddt.v10i5.4288

Abikesh Prasada Kumar Mahapatra, Shandong Maichuang Biopharmaceutical Co. Ltd., No. 1 Lutai Ave, Zibo City, Shangdong, CHINA

\section{Authors' contributions}

We declare that this work was done by the authors named in this article. APKM and JS conceived and designed the study. ZS, TD and ZG collected the information related to article. BP and IP drafted the manuscript. APKM supervised the work and assisted in the final drafting. JS contributed to final revision of the manuscript .All authors have read and approved the final manuscript.

\section{Introduction:}

Over the last 70 years, riding the "continuous quality improvement" wave set in motion by Walter Shewhart and W. Edwards Deming in the 1920s; many different industries have worked hard to better understand their processes in order to improve them. ${ }^{1}$

High quality production provides some advantages such as reduced scrap and increased market share. For this purpose there are some requirements to be met. First of all the organization should be cooperative and the quality should come first. On the other hand, in order to meet quality requirements of final product, quality should be achieved at every stage of production. ${ }^{2}$ Another way of achieving good quality during production is to use the statistical period techniques at every stage of production. If the production is statistically under control the process can continue and there is no need for a change in the process. However, if it is not statistically under control, the assignable causes should be discovered and removed from the process. Statistical quality control methods apply statistical principles and techniques at every stage of design, manufacturing, and servicing. Statistical quality control methods are quite different from traditional methods and they have made great contribution to improvements in companies dealing with mass production. ${ }^{3}$

Statistical methods - statistical process control (SPC), statistical acceptance plans, reliability analysis, statistics in improvement of processes (ANOVA, DOE) etc. belong to basic quality instruments. Statistical analysis can be performed in relation to measurable parameters or, on the 
grounds of alternative evaluation (yes/ no, conforming/ nonconforming). It can be formulated, that without a good measurement there is no good statistics, performance of a statistical analysis requires valuable data achieved from measurement systems of adequate quality. Measurement system analysis (MSA) is concerned with the evaluation of quality of measurement systems. Here, it should be emphasized that, first of all, the statistical properties decide about the quality of a measurement system and its ability for processes' monitoring with sufficient accuracy. 4

A key outcome of pharmaceutical validation studies is proving equipment, instruments and processes that are involved in the manufacture or testing of regulated materials are fit for purpose. Fit for purpose means that a system consistently performs the process it was designed to do when operated within normal limits. It can be quantified statistically by determining and measuring parameters with respect to acceptance limits.

Most parameters associated with manufacture and test measurements have a natural or normal distribution about an average value. The behavior of these parameters can be modeled and give accurate predictions for how well the parameter is controlled within defined limits. Accurate predictions can be made with small sample sets of data points (approximately twenty) using standard statistical functions such as those in MS Excel and other statistical software's. This analysis is known as a process capability (Cp) study. The system variance, expressed as 3 standard deviations above and below the system average ( 6 Sigma), is compared with the set limits of the parameter. ${ }^{5}$

The analysis of data is indispensable in determining the suitability of process/quality parameters as candidates for further statistical investigation. For the vast majority of parameters encountered in the pharmaceutical industry, understanding the concept of standard deviation and applying it to the measure of parameter variability, is all that is needed to draw useful conclusions regarding the ability of a system to control that parameter.

A critical tool for improving process understanding is "process capability analysis," which has proven its worth in automotive, aerospace and semiconductor manufacturing. Used to gauge process performance, the technique is now being used outside of manufacturing, to analyze transactional and design processes. ${ }^{6}$

Process capability analysis is also making its way into the pharmaceutical industry, where drug manufacturers and regulatory agencies are using it to characterize processes. This article introduces a roadmap for conducting a pharmaceutical process capability analysis, and explains some of the basic metrics involved. ${ }^{1}$

\section{Pharmaceutical Quality by Design (QbD) Objectives}

Pharmaceutical QbD is a systematic, scientific, risk-based, holistic and proactive approach to pharmaceutical development that begins with predefined objectives and emphases product and processes understanding and process control. The main objectives of pharmaceutical quality by designs are?:

1. Achieve meaningful product quality specifications that are based on assuring clinical performance

2. Increase process capability and reduce product variability and defects by enhancing product and process design, understanding, and control
3. Increase product development and manufacturing efficiencies

4. Enhance root cause analysis and post-approval change management

\section{Role of Process Capability in Pharmaceutical Development:}

The ICH Q10 states that in order to establish an effective pharmaceutical quality system, one of the objectives should be to 'Establish and Maintain a State of Control', which defined as the following:

$>$ To develop and use effective monitoring and control systems for process performance and product quality and

$>$ To provide the assurance of continued suitability and capability of processes

\section{Concept of Process Capability}

The concept of process capability first introduced in Statistical Quality Control Handbook by the Western Electric Company in 1956. Process capability is defined as the natural or inherent behavior of a stable process that is in a state of statistical control. Different organizations like ISO, AIAG, ASQ and ASTM published their guideline or manual on process capability index calculation. ${ }^{8}$

As we have seen, control charts are used to assess and monitor the stability of a process. The terms "stable" and "in control" are used to describe a process with only common causes of variation. However, a stable process might not be capable of producing the desired quality relative to specifications or tolerances. In other words, a stable process is not necessarily a capable process.

Capability indices have been developed to graphically portray that measure. Capability indices help to place the distribution of your process in relation to the product specification limits. Capability indices should be used to determine whether the process, given its natural variation, is capable of meeting established specifications. It is also a measure of the manufacturability of the product with the given processes. ${ }^{9}$

Process capability is a measurable property of a process which generally determines if the process is meeting its desired specification or not. The two main functions of process capability are: 10

* To measure the variability of the output of a process, and

* To compare that variability with a proposed specification, or product tolerance.

The output of this measurement is represented by a histogram and predicts how many parts will be produced out of specification (OOS) and is expressed as a process capability index.

\section{What is process capability?}

From a conceptual view it is a measure of the relationship between the voice of the process and the voice of customer (VOC). It is essentially a ratio of the customer requirement (specification) and the expected process variation.11

$$
\text { Process capability }=\frac{\text { Voice of customer }}{\text { Voice of process }}
$$

It is an expression of how well the process performs relative to the VOC. It is a prediction of how well the process will 
meet customer requirements in the future. A capable process is one in which almost all measurements of a feature produced by the process fall inside specification limits. There are several indices that are commonly used.

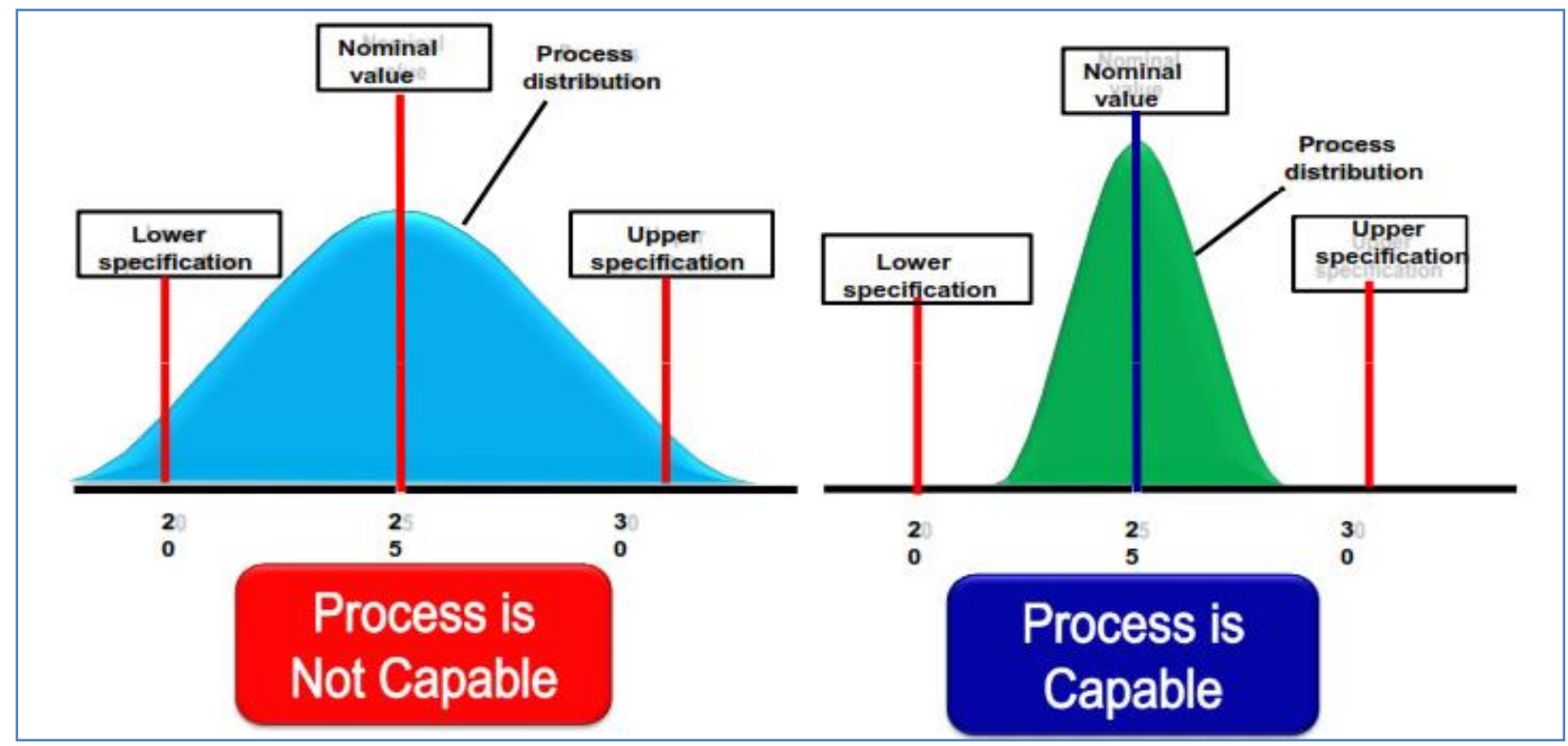

Figure 1: Capability of a process based on spread of process distribution across the specification

Capability indices can be used to compare the product/process matches and identify the poorest match (lowest capability). The poorest matches then can be targeted on a priority basis for improvement. If we sample a group of items periodically from a production run and measure the desired specification parameter, we will get subgroup sample distributions that can be compared to that parameter's specification limits. Two examples of this are represented below in fig 2 .

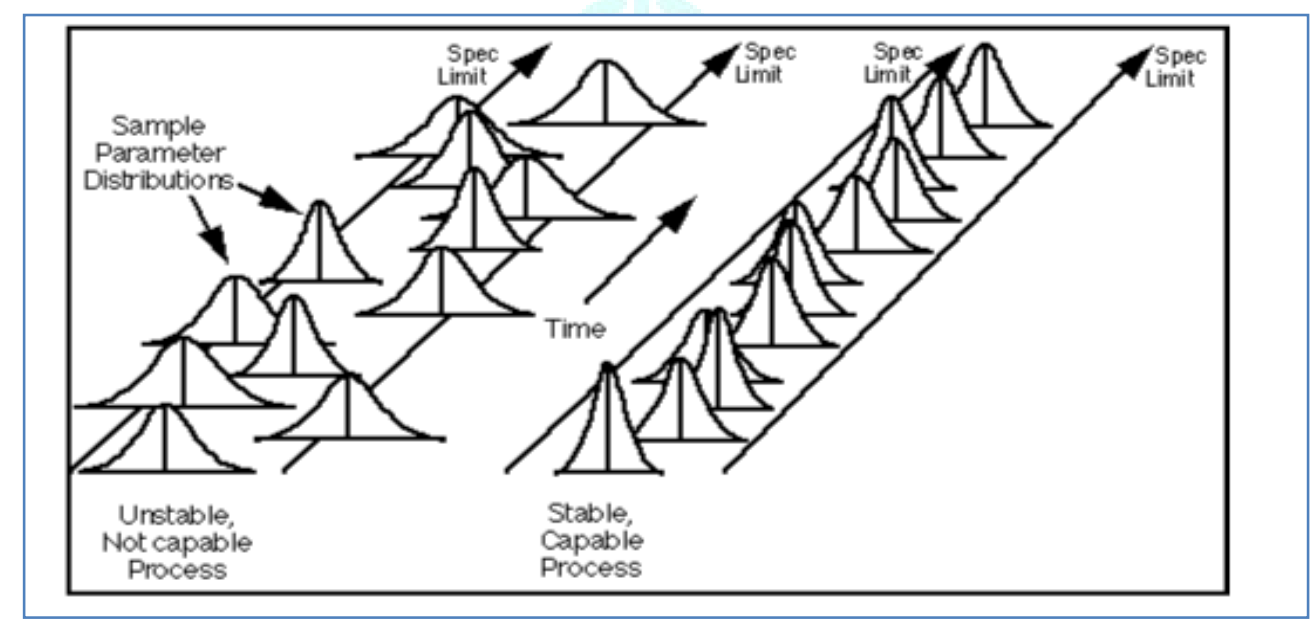

Figure 2: Capability of a sample process distribution based on specification limit 12

The diagram on the left side of fig 2 shows a series of sample distributions that fall inside of and outside of the specification limit. This is an example of an unstable, not capable process. The right side of the fig 2 shows all of the distributions falling within the specification limits. This is an example of a capable process. Process capability can be expressed with an index. Assuming that the mean of the process is centered on the target value, the process capability index $\mathrm{Cp}$ can be used. $\mathrm{Cp}$ is a simple process capability index that relates the allowable spread of the specification limits (spec range or the difference between the upper spec limit, USL, and the lower specification limit, LSL) to the measure of the actual, or natural, variation of the process, represented by 6 sigma, where sigma is the estimated process standard deviation.

Capability is a useful measure of how well a process keeps within the specification limits. For normally distributed measurements, capability is purely a function of the mean and variance of the process. Process capability studies compare the variability (or spread) of a stable process to the width of the specification limits, as shown in figure 3 . 


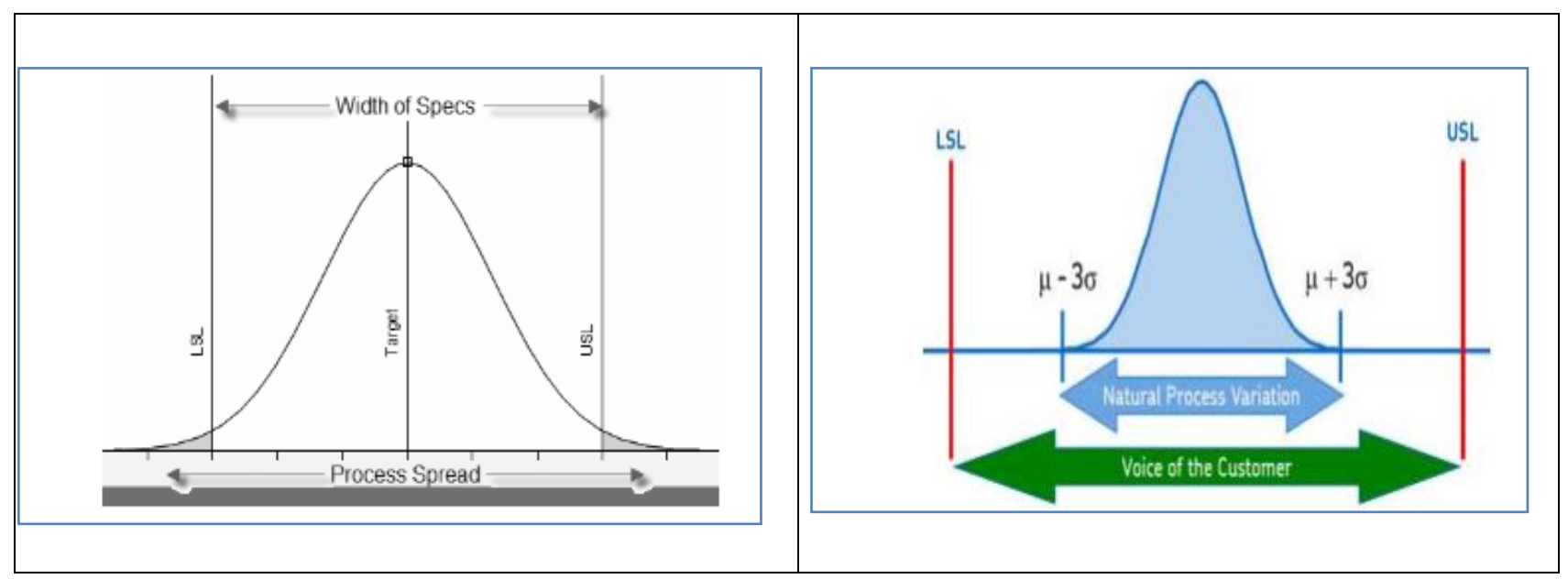

Figure 3: Relation of process capability studies with process width and specification width (VOC) ${ }^{14}$

\section{Definitions and formulas associated with common capability indices ( $\mathrm{Cp} / \mathrm{Cpk})$}

\section{Definition of Cp}

The equation for Cp is often written ET / NT. ET stands for Engineering Tolerance, which is the width between the specification limits. NT stands for Natural Tolerance, which is the width that should contain almost all of the data from the process. Traditionally, NT is 6 times the standard deviation. 13

We often describe $\mathrm{Cp}$ as the capability the process could achieve if the process was perfectly centered between the specification limits.

\section{Definition of Cpk 13}

The equation for Cpk is more complicated:

$$
\mathrm{Cpk}=\frac{[\text { minimum }(\text { mean }-\mathrm{LSL}, \mathrm{USL}-\text { mean }]}{0.5 * \text { Natural tolerance }}
$$

Where,

\section{LSL stands for Lower Specification Limit and}

USL stands for Upper Specification Limit.

Often Cpk described as the capability the process is achieving whether or not the mean is centered between the specification limits. A variety of indices are available to quantify capability. The most common measures are $\mathrm{Cp}, \mathrm{Cpk}$, $\mathrm{Cpl}$, and $\mathrm{Cpu}$

The use of the capability index depends on the situation: 14
* If it is important that you hit a target, then Cpk is the best choice.

* If the target is concerned about staying within a onesided lower or upper specification limit, then $\mathrm{Cpl}$ (lower) or Cpu (upper) should be used.

* If there is a need to make sure the variation is under control, given it is relatively easy to steer the mean to the target, $\mathrm{Cp}$ is the best measure.

$\begin{array}{ll}C P U=\frac{(U S L-\mu)}{\left(3 * \sigma_{\text {Within }}\right)} & P P U=\frac{(U S L-\mu)}{3^{*} \sigma_{\text {Oerall }}} \\ C P L=\frac{(\mu-L S L)}{\left(3^{*} \sigma_{\text {Within }}\right)} & P P L=\frac{(\mu-L S L)}{3^{*} \sigma_{\text {Overall }}} \\ C p k=\operatorname{minimum}\{C P U, C P L\} & P p k=\text { minimum }\{\text { PPU, PPL }\}\end{array}$

Figure 4: Formula associated with different capability indices 15,20

\section{Relationship between Cp and Cpk}

The two statistics have a lot in common. The smaller the standard deviation, the greater both statistics are. In fact, under the right conditions, $\mathrm{Cp}$ and $\mathrm{Cpk}$ have exactly the same value.

If the process is in statistical control, via "normal" SPC charts, and the process mean is centered on the target, then $\mathrm{Cp}$ can be calculated as follows:

Table 1: Significance of different value of $\mathrm{Cp}$ 16,18

\begin{tabular}{|l|l|l|}
\hline \multicolumn{3}{|l|}{ Cp = (USL - LSL) / 6 sigma } \\
\hline $\mathrm{Cp}<1$ & $\begin{array}{l}\text { The process is not } \\
\text { capable }\end{array}$ & $\begin{array}{l}\text { The process variation exceeds specification, and a significant number of defects are } \\
\text { being made. }\end{array}$ \\
\hline $\begin{array}{l}\mathrm{Cp}=1 \text { to } \\
1.33\end{array}$ & $\begin{array}{l}\text { A barely capable } \\
\text { process }\end{array}$ & $\begin{array}{l}\text { The process is just meeting specifications. A minimum of 3\% defects will be made and } \\
\text { more if the process is not centered. }\end{array}$ \\
\hline $\mathrm{Cp}>1$ & $\begin{array}{l}\text { The process is not } \\
\text { capable }\end{array}$ & $\begin{array}{l}\text { The process variation is less than the specification; however, defects might be made if } \\
\text { the process is not centered on the target value. }\end{array}$ \\
\hline $\mathrm{Cp}>1.33$ & $\begin{array}{l}\text { A highly capable } \\
\text { process }\end{array}$ & $\begin{array}{l}\text { This process will produce conforming products as long as it remains in statistical } \\
\text { control. The process owner can claim that the customer should experience least } \\
\text { difficulty and greater reliability with this product. This should translate into higher } \\
\text { profits. }\end{array}$ \\
\hline
\end{tabular}




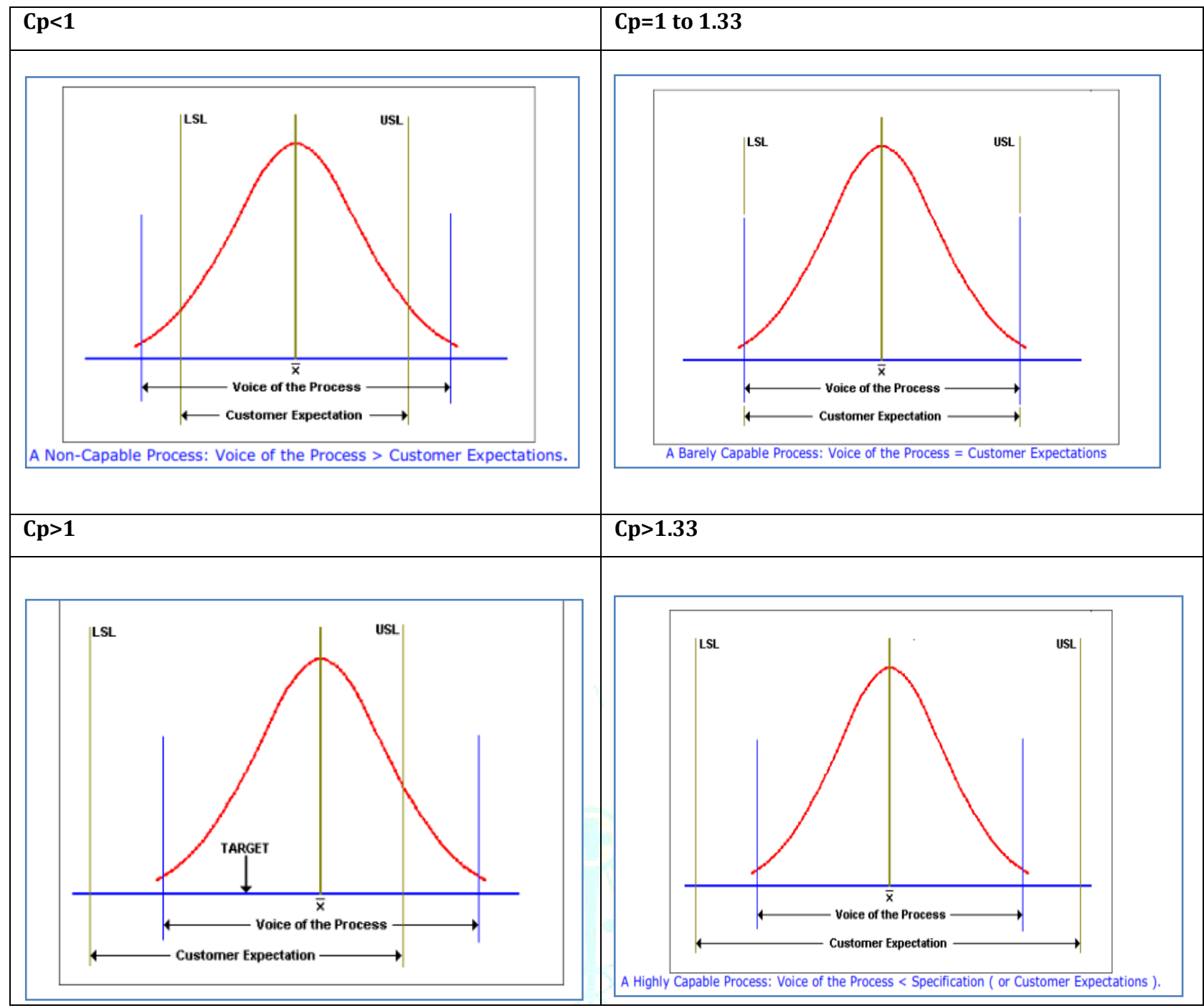

Figure 5: Significance of different value of $\mathrm{Cp}^{17}$

While Cp relates the spread of the process relative to the specification width, it does not address how well the process average, $\mathrm{X}$, is centered to the target value. $\mathrm{Cp}$ is often referred to as process "potential".

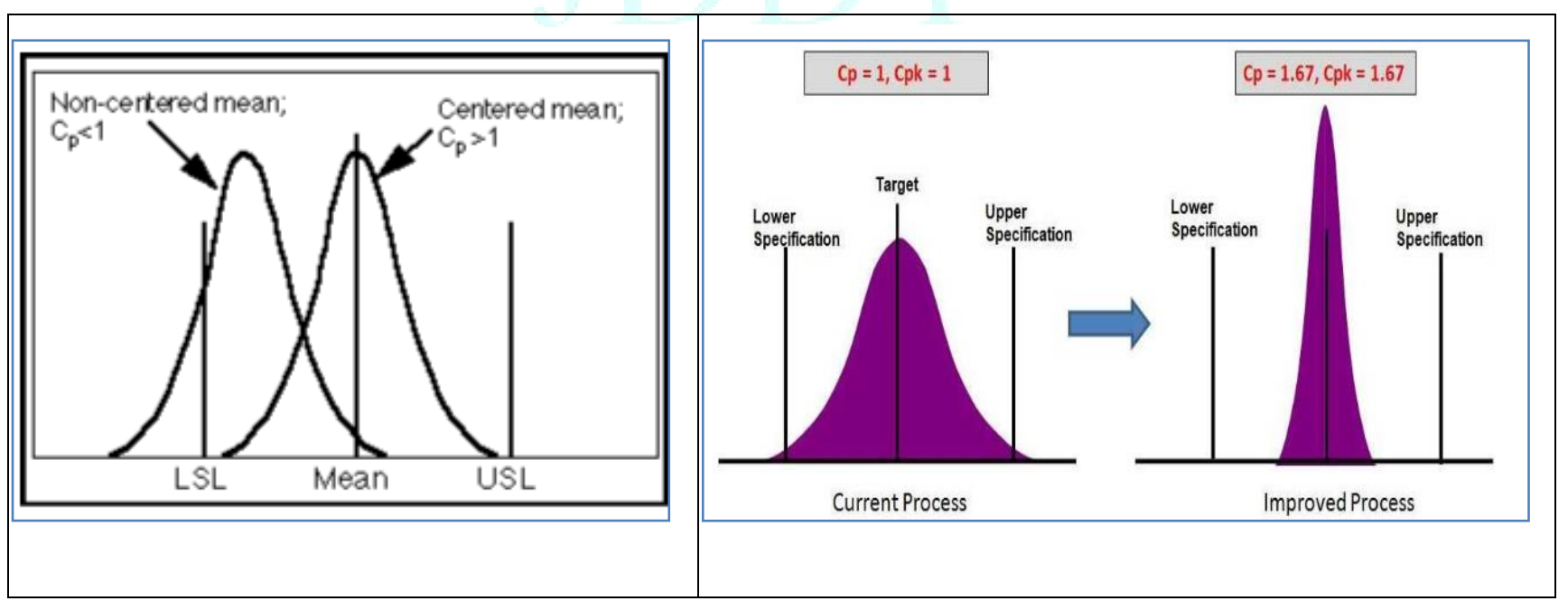

Figure 6: Graphical presentation of $\mathrm{Cp}$ with respect to distribution of mean ${ }^{12}$

Cpk measures not only the process variation with respect to allowable specifications; it also considers the location of the process average.
Cpk is taken as the smaller of either $\mathrm{Cpl}$ or $\mathrm{Cpu}$ where

$$
\mathrm{Cpl}=\frac{\mathrm{X}-\mathrm{LSL}}{3 \text { sigma }}, \quad \mathrm{Cpu}=\frac{\mathrm{USL}-\mathrm{X}}{3 \text { sigma }}
$$


Where, $\mathrm{X}$ is the process mean

Many companies are establishing specific process capability targets. They may typically start with 1.33 for supplier qualification and have an expected goal of 2.0. If the process is near normal and in statistical control, Cpk can be used to estimate the expected percent of defective material.

\section{Cpk values and its corresponding non-conforming rate}

The value of Cpk closely related with the \% of conforming level with respect to type of specification i.e. unilateral or bilateral specification.

Table 2: Cpk value and its corresponding non-conforming rate with respect to specification

\begin{tabular}{|c|c|c|c|c|c|}
\hline \multirow{2}{*}{ Cpk Value } & \multirow{2}{*}{$\begin{array}{l}\text { Sigma } \\
\text { value }\end{array}$} & \multirow{2}{*}{$\begin{array}{l}\text { Area under normal curve } \\
\text { ( } \% \text { conforming level } * \text { ) }\end{array}$} & \multicolumn{2}{|c|}{$\begin{array}{l}\text { Non-conforming parts per } \\
\text { million(ppm) }\end{array}$} & \multirow{2}{*}{$\begin{array}{l}\text { Capability } \\
\text { rating }\end{array}$} \\
\hline & & & $\begin{array}{c}\text { Unilateral } \\
\text { specification }\end{array}$ & $\begin{array}{c}\text { Bilateral } \\
\text { specification* }\end{array}$ & \\
\hline 0.333 & 1 & 68.27 & 158650 & 317300 & Terrible \\
\hline 0.667 & 2 & 95.45 & 22750 & 45500 & Poor \\
\hline 1.0 & 3 & 99.73 & 1350 & 2700 & $\begin{array}{l}\text { Marginally } \\
\text { capable }\end{array}$ \\
\hline 1.333 & 4 & 99.9936 & 32 & 64 & Capable \\
\hline 1.667 & 5 & 99.99994 & 0.3 & 0.6 & Good \\
\hline 2.0 & 6 & 99.999998 & 0.001 & 0.002 & Excellent \\
\hline
\end{tabular}

* Process mean is centered at middle of the specification limits and has normal distribution

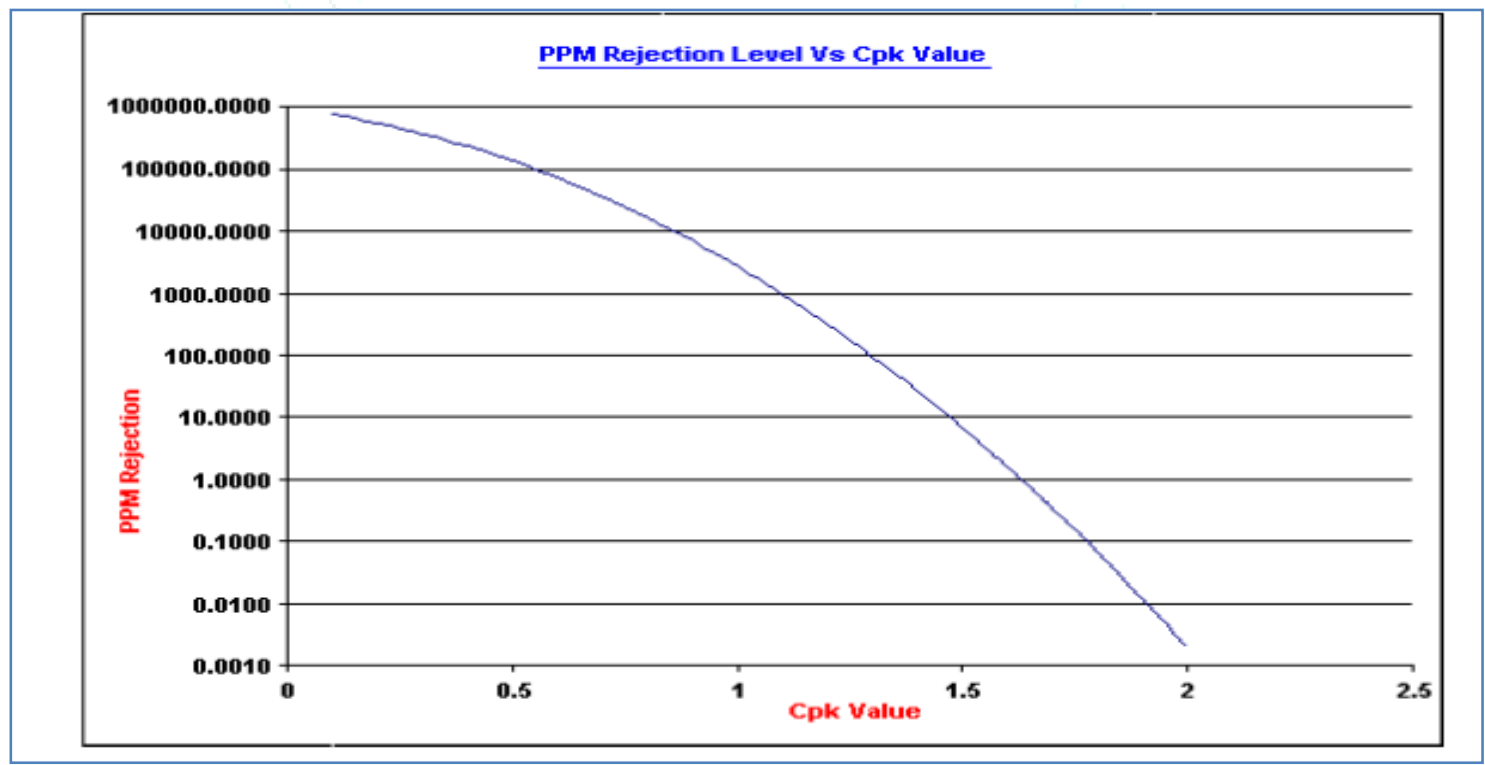

Figure 7: PPM rejection level Vs Cpk value 18

A process with Cpk of 2.0 (+/- 6 sigma capability), i.e., the process mean is 6 sigma away from the nearest specification can be expected to have no more than 0.002 nonconforming parts per million. This process is so good that even if the process mean shifts by as much as $+/-1.5$ sigma the process will produce no more than 3.4 non-conforming parts per million.

Process Capability Studies are designed to see what the process is "capable" of doing under controlled conditions. The studies look at how capable the process is given ideal conditions over a short period of time (such as one hour to twenty-four hours.) The individual who is mainly responsible for a process capability study is a Process Engineer. The Process Engineer must keep in mind the following two considerations when conducting the study. ${ }^{19,12}$ $\checkmark \quad$ Eliminate or minimize special causes of variation, for example using the same operator, same batch of material, same machine and so on.

$\checkmark$ Collect a minimum of 50 consecutive pieces in at least 10 subgroups of 5 .

The benefit of conducting a process capability study allows determining the "short" term stability and capability of a process.

\section{Relationship between Cpk and Ppk}

The goal of capability analysis is to ensure that a process is capable of meeting customer specifications, and the capability statistics such as Cpk and Ppk to make that assessment. The formulas for $\mathrm{Cpk}$ and Ppk for normal (distribution) process capability, are nearly identical: 
The only difference lies in the denominator for the upper and lower statistics: Cpk is calculated using the WITHIN standard deviation, while Ppk uses the OVERALL standard deviation. The details surrounding the formulas for the standard deviations, it can be foresee that the within standard deviation as the average of the subgroup standard deviations, while the overall standard deviation represents the variation of all the data. 20

Table 3: Difference between Cpk and Ppk 20

\begin{tabular}{|l|l|}
\hline \multicolumn{1}{|c|}{ Cpk } & \multicolumn{1}{|c|}{ Ppk } \\
\hline Only accounts for the variation WITHIN the subgroups & $\begin{array}{l}\text { Accounts for the OVERALL variation of all } \\
\text { measurements taken }\end{array}$ \\
\hline Does not account for the shift and drift between subgroups & $\begin{array}{l}\text { Theoretically includes both the variation within } \\
\text { subgroups and also the shift and drift between them }\end{array}$ \\
\hline $\begin{array}{l}\text { Is sometimes referred to as the potential capability because it } \\
\text { represents the potential of the process has at producing parts } \\
\text { within spec, presuming there is no variation between } \\
\text { subgroups (i.e. over time) }\end{array}$ & \\
\hline
\end{tabular}

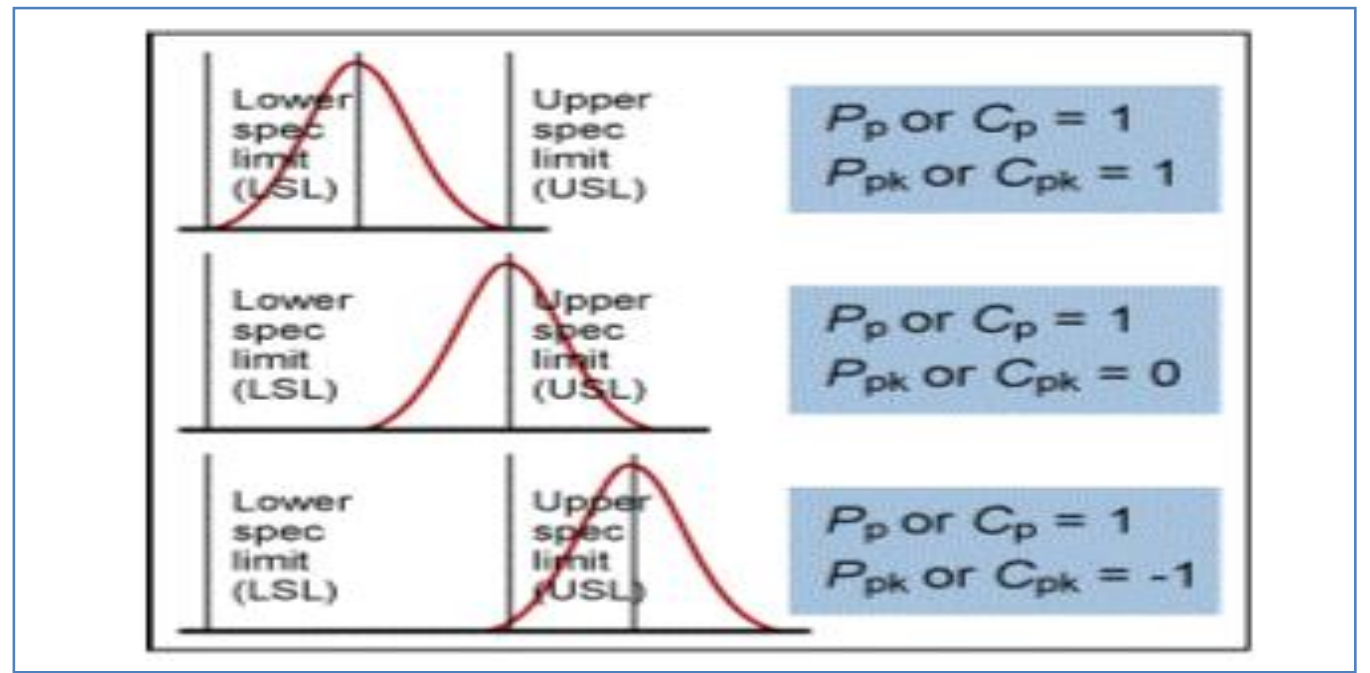

Figure 8: Graphical presentation for relationship between $\mathrm{Cp}$ and $\mathrm{Cpk}{ }^{11}$

\section{Short and long term estimation of capability}

There are different ways to estimate the standard deviation. We can calculate a short term estimate, or an overall, long-term estimate. The short-term estimate can be used if data were collected using rational sub grouping. This estimate is a within-subgroup estimate of the standard deviation, which should be free of special causes. When the short-term estimate the capability indices are labeled $\mathrm{C}_{\mathrm{p}}$ and $\mathrm{C}_{\mathrm{pk}}$. Because $\mathrm{C}_{\mathrm{pk}}$ takes into consideration centering, it is sometimes called actual capability. ${ }^{21}$

The long-term estimate of the standard deviation is simply the standard deviation of all of the data. If the process is not stable, this will include special causes of variation. When the long-term estimate of the standard deviation is used, the indices are generally referred to as process performance indices. These indices are labeled $\mathrm{P}_{\mathrm{p}}$, for potential performance, and $\mathrm{P}_{\mathrm{pk}}$, for actual performance.
The same formulas are used to calculate the process performance indices, but the long-term estimate of the standard deviation is used instead of the short-term estimate. If the process is not stable, $\mathrm{P}_{\mathrm{p}}$ and $\mathrm{P}_{\mathrm{pk}}$ will be lower than $\mathrm{C}_{\mathrm{p}}$ and $\mathrm{C}_{\mathrm{pk}}$.

\section{Examples of the difference between Cpk and Ppk} 20,22

Both Cpk and Ppk are interrelated. The relationship of these two capability indices can be easily understood by graphical presentation with suitable example. However, to understand the relationship, the two below two condition. The below two probable conditions (example 1 and example 2) explains the difference between the two capability indices illustratively

For illustration, let's consider a data set where 5 measurements were taken every day for 10 days. 


\section{Example 1 - Similar Cpk and Ppk}

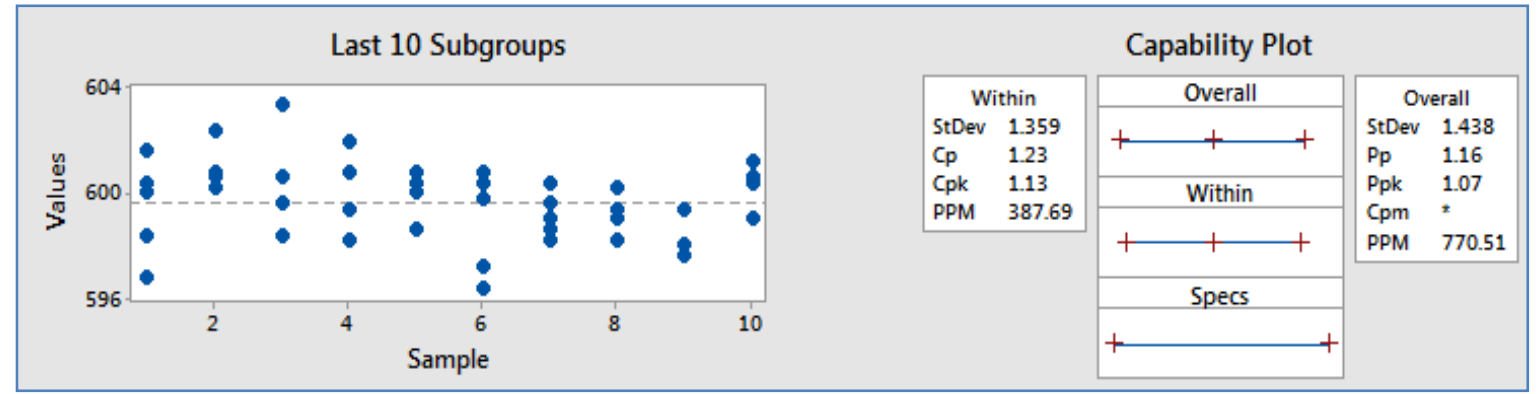

Figure 9: Difference between Cpk and Ppk with similar Cpk and Ppk value

As the graph on the left side shows, there is not a lot of shift and drift between subgroups compared to the variation within the subgroups themselves. Therefore, the within and overall standard deviations are similar, which means Cpk and Ppk are similar, too (at 1.13 and 1.07, respectively).

\section{Example 2 - Different Cpk and Ppk}

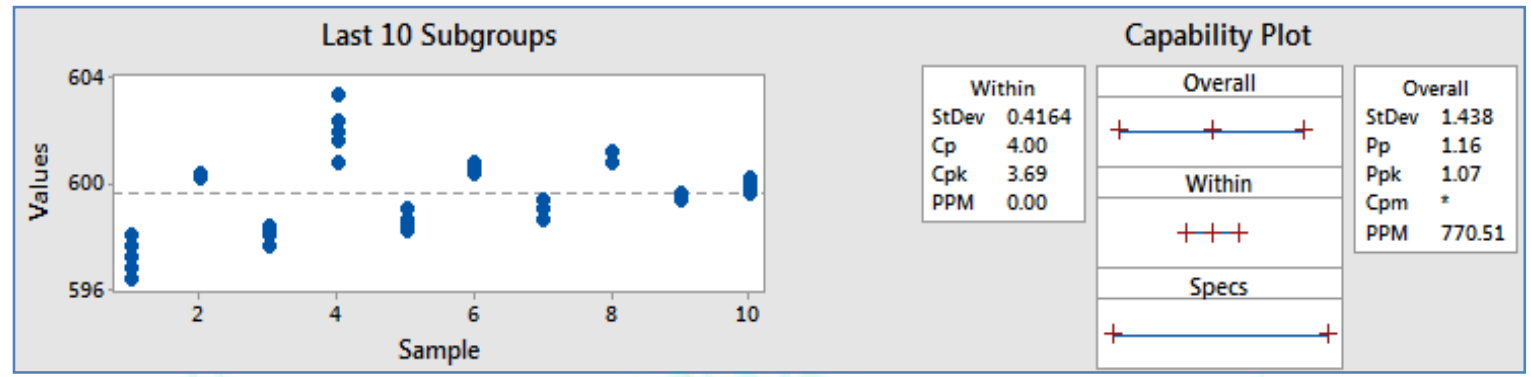

Figure 10: Difference between Cpk and Ppk with different Cpk and Ppk value

In this example, the same data and subgroup size was used, but the data around, moving it into different subgroups.

Since the same data was used, the overall standard deviation and Ppk did not change. But that's where the similarities end.

The observed Cpk statistic is 3.69, which is much better than the 1.13 we got before. Looking at the subgroups plot, the reason of increased Cpk can be identified. The graph shows that the points within each subgroup are much closer together than before. So less variability within each subgroup equals a smaller within standard deviation and that gives us a higher Cpk.

\section{Use of capability indices (Cp, Cpk, Pp and Ppk)}

There is a time and a place to use each of these numbers depending on the individual situation. Because $\mathrm{Cp}$ and $\mathrm{Cpk}$ use estimated sigma, and Pp and Ppk use actual sigma, they have different use.

$>\mathrm{Cp}$ and $\mathrm{Cpk}$ consider the deviation mean within rational subgroups, while Pp and Ppk set the deviation based on the studied data.

$>$ In most of the practices, when process is unstable or has just begun then Pp and Ppk values of that process are considered for statistical analysis.

$>$ When the process is stable and in control then Cp and Cpk values are considered for statistical analysis.

Table 4: Use of capability indices (Cp, Cpk, Pp and Ppk) ${ }^{23}$

\begin{tabular}{|l|l|l|}
\hline & \multicolumn{1}{|c|}{$\begin{array}{c}\text { New process or process not under } \\
\text { statistical control }\end{array}$} & \multicolumn{1}{c|}{$\begin{array}{c}\text { Existing process under } \\
\text { statistical control }\end{array}$} \\
\hline Measure of spread fit & $\mathrm{Pp}$ & $\mathrm{Cp}$ \\
\hline Measure of centering & $\mathrm{Ppk}$ & $\mathrm{Cpk}$ \\
\hline
\end{tabular}




\section{Analogy with Archery}

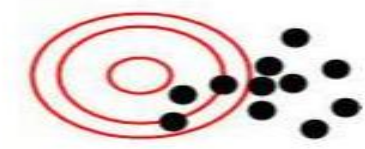

a) Just began learning. Aims at center but the result is hilarious ( Pp ok but Ppk not ok)

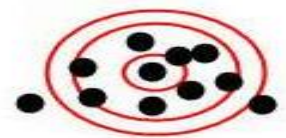

b) Finally shot the center but is still amateur ( $\mathrm{Pp}$ and Ppk ok)

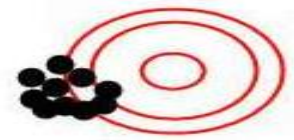

c) Decides to concentrate on controlling the spread and finally increases accuracy (Good Cp but bad Cpk)

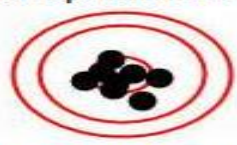

d) After gaining stability finally targets the center and the result is excellent (Good Cp and $(\mathrm{pk}$ ).

Figure 11: Representation for $(\mathrm{Pp} / \mathrm{Ppk})$ and $(\mathrm{Cp} / \mathrm{Cpk})$ with respect to spread and centralization of process 23

$\mathrm{Cp}$ and Cpk can be used to measure a system's potential capabilities, while Pp and Ppk measure the system's actual performance. A tabular form for the difference between the capability indices ( $\mathrm{Cp}$ and $\mathrm{Pp}$ vs. Cpk and Ppk) presented in the table 5 .

Table 5: Difference between capability indices (Cp and Pp vs. Cpk and Ppk) 24, 25

\begin{tabular}{|l|l|}
\hline $\begin{array}{l}\text { Cp and Pp } \\
\text { (Cp = Process Capability ; } \\
\text { Pp = Process Performance) }\end{array}$ & $\begin{array}{l}\text { Cpk and Ppk } \\
\text { (Cpk = Process Capability Index ; } \\
\text { Ppk = Process Performance Index })\end{array}$ \\
\hline $\begin{array}{l}\text { Both Cp and Pp are monitoring indices for the spread } \\
\text { of your process compared to the specification spread. }\end{array}$ & $\begin{array}{l}\text { Cpk and Ppk are used to indicate the spread of process } \\
\text { about the centre. }\end{array}$ \\
\hline $\begin{array}{l}\text { They do not provide information about process } \\
\text { centralization. }\end{array}$ & $\begin{array}{l}\text { They give us the idea of how well the process is } \\
\text { centered or how much it has deviated from the centre. }\end{array}$ \\
\hline $\begin{array}{l}\text { They tell us whether the process is capable or not but } \\
\text { not whether the process is acceptable. }\end{array}$ & $\begin{array}{l}\text { They can tell us whether the process is acceptable or } \\
\text { not as well as whether the process is capable or not. }\end{array}$ \\
\hline $\begin{array}{l}\text { Cp or Pp = (USL-LSL)/6s } \\
\text { Where; USL = Upper Specification Limit } \\
\text { LSL = Lower Specification Limit }\end{array}$ & $\begin{array}{l}\text { Cpk or Ppk = Min of [(Mean - LSL)/3s] or[(USL- } \\
\text { Mean)]/3s } \\
\text { Where; USL = Upper Specification Limit } \\
\text { LSL = Lower Specification Limit }\end{array}$ \\
\hline
\end{tabular}

\section{Importance of Cpk or Ppk (Which is most valuable/powerful) 26}

The reality is that $\mathrm{Cpk}$ is a better estimate of the potential of process. It represents the best process can do and that is when the within subgroup variation is essentially the same as the between subgroup variation. This is what it means to be in statistical control. If the process is in statistical control, Cpk is essentially the same as Ppk. So, in this case there is no need of Ppk.

However, if the process is not in statistical control and have something to work on $\mathrm{Cpk}$ and Ppk are pretty well meaningless - except for the fact those values of Cpk and Ppk that are widely different are indications that the process is not in statistical control.

\section{Identifying a poor capability Process}

Process capability indices, in partnership with control charts on critical process variables, help to identify processes that are performing poorly. Stability is always evaluated using control charts. Capability is evaluated based on the ability to meet customer specifications. A capable process must be stable, but a stable process might not be capable. The best processes are both stable and capable. The worst process is one that is not stable and not capable. This type of graph is called a process performance graph. ${ }^{28}$

The stability index is a measure of the stability of the process. It is the ratio of the overall (long-term) standard deviation, or sigma, to the within-subgroup (short-term) sigma. For a stable process, the overall and within 
estimates of the standard deviation are about the same, and the stability index is close to 1 . An unstable process has a large overall standard deviation relative to the within estimate. In this case, the stability index will be larger than 1.

A process performance graph can provide insights into the types of problems needed to address to improve the performance of a process. If the process is unstable, there is need to identify the special causes and address them. If the process is not capable, then there is too much variability or the process is off target, or both. 28

It is well known that $C_{p}$ measures the potential capability and that $\mathrm{C}_{\mathrm{pk}}$ measures actual capability. If there is a difference between $C_{p}$ and $C_{p k}$ (or $P_{p}$ and $P_{p k}$ ), the process is off target. The target index is a measure of how far off target a process is. The target index measures the number of standard deviations the mean is from the target. If the target index is 1 , then the mean is 1 standard deviation from the target

\section{Taguchi capability index 10}

Another index Cpkm, also known as the Taguchi capability index, estimates process capability around a target ( $\mathrm{T})$ and assumes process output is approximately normally distributed. It is given by

$$
\text { Cpkm }=\frac{\mathrm{Cpk}}{\sqrt{1+(\mu-T / \sigma)^{2}}}
$$

Where, $\mathrm{Cpkm}=$ Taguchi capability index

$\mathrm{Cpk}=$ Process capability index

$\mathrm{M}=$ Process average

$\mathrm{T}=$ Expected target

$6=$ Standard deviation of the process

The distinction between Cpkm and Cpk lies with target and the specification limits. Taguchi emphasized more on the target value than the specification limits. Thus, while Cpk relates to the specification limits, Cpkm relates to the target value, which is narrower than the former.

\section{Steps for a Capability Analysis 11}

To assure valid results when performing a capability analysis, following steps are followed.

\section{Generate I and MR charts.}

Start with the range chart and determine stability. Are all points inside of the control limits? If yes, the process is stable and the analysis can move forward. If no, the process is unstable and this must be addressed before moving on.

\section{Look at individuals chart.}

Are there any indications of out-of-control data per the rules of process control? If yes, the process is out of control and this must be addressed before advancing in the capability analysis. If no, then the process is in control and analysis may proceed.

\section{Generate a normal probability chart and test for normality}

- If a distribution is close to normal, the normal probability plot will be close to a straight line. Some statistical software's report the Anderson-Darling statistic. The null hypotheses for this test is that the distribution is normal; thus, to conclude that the data is normal, the p-value must be greater than 0.05 (typically).

- If the data is normal, then assess capability. Otherwise the data may need to be transformed. A popular transformation is the Box-Cox transformation. (Alternatively, you could use a process capability index that applies to non-normal distributions. One statistic is called Cnpk [for non-parametric Cpk].

\section{Assess process capability.}

\section{Process for calculating process capability}

To calculate process capability, there is requirement of three things:

- Process average estimate

- Process standard deviation estimate

- Specification limit

This is true for both Cpk and Ppk and it follows the assumption that the data are normally distributed.

Process capability indices represent a ratio of how far a specification limit is from the average to the natural variation in the process. The natural variation in the process is taken as being 3 times the process standard deviation.

The process capability index is then given by:

$$
\text { Process capability index }=\frac{(\mathrm{USL}-\text { Average })}{3 \mathrm{~S}}
$$

To calculate process capability, there is need of estimation of the process average and the process standard deviation (i.e., within and between the group standard deviation).

\section{Advantages of process capability}

Different advantages associated with the process capabilities are

1. It tells us the condition of the output.

2. It compares the natural variation with the specification of customers.

3. It tells us whether the process is capable to produce the desired output or not.

4. It compares two or more processes, to tell which process is most capable.

5. It helps to predict the variations occurring in process.

6. It helps to identify and eliminate the special causes.

\section{Process Capability Assumptions ${ }^{11}$}

When calculating process capability ( $\mathrm{Cp}$ or $\mathrm{Cpk}$ ), there are three key assumptions:

$$
\begin{array}{ll}
\checkmark & \text { Large sample size } \\
\checkmark & \text { Stable process } \\
\checkmark & \text { Normal distribution }
\end{array}
$$

When these assumptions are not met, the values are not valid. Most capability index estimates are valid only if the sample size used is "large enough," which is generally thought to be about 30 or more independent data values.

\section{Process capability road map in pharmaceutical development}

The new modern manufacturing environment is characterized by increased product diversity and greatly 
reduced product life cycle. Today's market situation forces manufacturers to make products with high quality, low manufacturing cost and at the same time to produce broader variety of products. The competition in marketplaces requires quickly renew existing products and develop new ones. The large number of product variants and low manufacturing volumes makes it difficult to design product and process. The key part of product development cycle is the conceptual design stage that greatly influences the resulting cost, quality, product manufacturability and its life cycle parameters. ${ }^{28,29}$

Requirements of a good product design are defined by its performance and manufacturability. A good design can only be made under consideration of the manufacturing processes. Being in control of a manufacturing process using statistical process control (SPC) is not enough. An "incontrol" process can produce bad or out-of-spec product. Manufacturing processes must meet or be able to achieve product specifications. Further, product specifications must be based on customers' requirements.
There is sequential approach through which the customer requirement is fulfilled for product development. The different steps involved are 30

1. Selection of critical parameters

2. Collection of data for the study design

3. Establishment of proper control of process (by measuring and controlling parameters such as $\mathrm{X}$ bar chart and R chart)

4. Analysis of Process data (standard deviation, process mean or calculation of process capability)

5. Establishment of process monitoring system

The details of the sequential approach for the process capability road map in pharmaceutical development are described below in fig 12 .

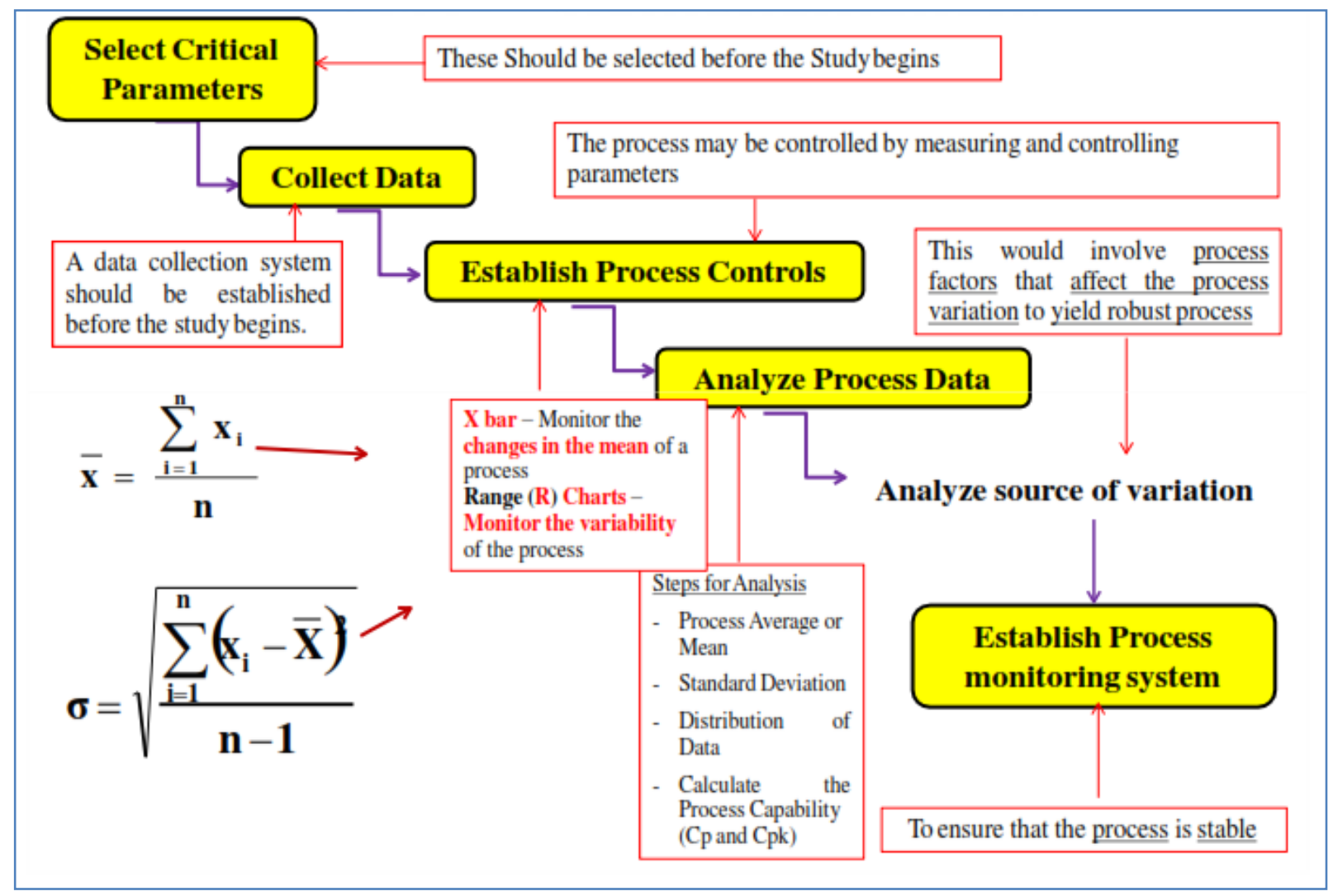

Figure 12: Rod map of process capability in pharmaceutical product development

\section{How Cpk useful to improve the consistently in process capabilities}

1. Perform a Capability Analysis: Evaluate the Cpk of the process and make a decision whether there is a need for improvement

2. Explore the relationship: If there is a need for improvement, the link between the potential cause and effect are identified (the process parameters which may need optimization are identified). E.g. It is unusual that a particular CQA is dependent only one CPP, dissolution failure may be due to particle size distribution of API, excipients, blend, compression, coating or all the above.
3. Generate a Hypothesis: The relation between the potential causes and effect are identified may be by step-wise regression (identify where there is highest variability and also, how the changes in the CPP in various steps affect the CQA). e.g. this is where one can test how the compression parameters affect the dissolution and establish a co-relation if possible.

4. Improve: Work on creating an optimum set of the key process factors which result in an improved predicted $\mathrm{Cpk}$, consistent with the goal of delivering a significant improvement in process capability. 


\section{Conclusion:}

Capability analysis helps to determine the ability for manufacturing between tolerance limits and engineering specifications. Capability analysis can be applied not only to production period but also to a machine or machine tool. Capability analysis gives the information about changes and tendencies of the system during production. It is used to determine the system tendencies between tolerance limits.

Process capability indices can be a powerful tool by which to ensure drug product quality and process robustness. Case studies from both innovator and generic pharmaceutical industries demonstrated that process capability indices can be a useful tool by which to drive operation excellence and ensure delivery of superior product quality. Use of process capability indices should always go hand in hand with enhanced scientific understanding of the product and process.

In summary, determining process capability provides far more insight into any pharmaceutical process performance than simply computing the percentage of batches that pass or fail each year. Remember that high process capability guarantees a high percentage of passing batches, but a high percentage of passing batches cannot guarantee high process capability.

Process capability analysis is not the only technique available for improving process understanding. However, given FDA's new science-based regulatory framework and the promise of "safe haven" for manufacturers that demonstrate process knowledge, the practice promises to become a more important tool for pharmaceutical manufacturing professionals in the future.

\section{Acknowledgements}

The authors express their sincere thanks to the management of Shandong Maichuang Biopharmaceutical Co. Ltd, China and Mrs. Anita Nanda, HOD of special education DPMIASSE\&T, Kodola, Ganjam, India for providing necessary support to carry out the above work.

\section{Conflicts of interests}

The authors declare that they have no competing interests.

\section{References}

1. A process capability road map. Article/2004, USA: Pharma manufacturing. 2004. Available at: https://www.pharmamanufacturing.com/articles/2004/155/ . Accessed on July 26, 2020.

2. Jabnoun $\mathrm{N}$, "Control processes for total quality management and quality assurance" Work Study; 51(4):182-190.

3. Sindhe JS, Katikar RS, "Importance of process capability and process performance indices in machine tool" International Journal of Research in Engineering \& Applied Sciences, 2012; 2(2):1211-1217.

4. Czarski A, Matusiewicz P, "Influence of measurement system quality on the evaluation of process capability indices "Metallurgy and Foundry Engineering, 2012; 38(1):25-32.

5. PharmOut white paper: Process Capability: Pharm Out. 2017. Available at: https://www.pharmout.net/downloads/whitepaper-process-capability.pdf. Accessed on Aug 1, 2020.

6. Chaudhry SS, Higbie JR "Practical implementation of statistical process control in a chemical industry" Pharmaceutical Research, 1989; 6(5).

7. Yu YL, "Pharmaceutical Quality by Design: Product and Process Development Understanding, and Control" Pharmaceutical Research, 2008; 25(4):781-791.

8. Statistical quality control hand book. 6 th ed. USA: Western electric Co. Inc.; 1982. P. 3-5.
9. Chen KS, Huang ML, Li RK, "Process capability analysis of an entire product" International Journal of Production Research, 2001; 39(17):4077-4087.

10. Kiran DR.Total Quality Management: Key Concepts and Case Studies. 2017. BSP Books Pvt. Ltd. Published by Elsevier Inc.; 2017.P.257-259.

11. Scott R, Process capability-The basics: part I. USA: Process central. $2020 . \quad$ Available at: http://processnews.blogspot.com/2020/05/processcapability-the-basics-part-1.html. Accessed on Aug 1, 2020.

12. Process Capability and Product Design.2019. Available at: https://www.npd-solutions.com/proccap.html. Accessed on Aug 1, 2020.

13. Minitab blog: Process Capability statistics: Cpk and Ppk, Working Together.2013. Available at https://blog.minitab.com/blog/statistics-and-qualityimprovement/process-capability-statistics-cp-and-cpkworking-together. Accessed on Aug 6, 2020.

14. Sall J, Lehmann A, Stephens M, Loring S. JMP start statistics- A Guide to Statistics and Data Analysis using JMP. 6 th edition.USA: Cary, NC: SAS Institute Inc: 2017.P.564-567.

15. Chen KS, Huang ML, Hung YH, "Process capability analysis with the application of Cpm" International Journal of Production Research, 2008; 46(16):4483-4499.

16. Six sigma-materials: Process Capability indices.2020. Available at: https://www.six-sigma-material.com/Process-CapabilityIndices.html. Accessed on Aug 6, 2020.

17. Kane EV, "Process Capability Indices" Journal of Quality Technology, 1986; 18(1):41-52.

18. Kapadia M, Measuring your Process Capability. India: Symphony Technologies. Available at:http://www.symphonytech.com/articles/pdfs/processcapa bility.pdf. Accessed on Aug 1, 2020.

19. Jeang A, "Optimal process capability analysis for process design" International Journal of Production Research, 2008; 1 33.

20. Minitab blog: Process Capability statistics: Cpk vs Ppk.2016. Available at: https://blog.minitab.com/blog/processcapability-statistics-cpk-vs-ppk. Accessed on Aug 6, 2020.

21. JMP user community discussions: Short term (Cpk) and Long term (Ppk) capability in JMP.2019. Available at: https://community.jmp.com/t5/Discussions/Short-TermCpk-and-Long-Term-Ppk-Capability-in-JMP/td-p/218668. Accessed on Aug 10, 2020.

22. Wooluru Y, Swamy DR, Nagesh $P$ “ The process capability analysis- A tool for process performance measures and metrics- A case study" International Journal of Quality Research, 2014; 8(3):399-416

23. Hessing T, Process Capability ( $\mathrm{Cp}$ and $\mathrm{Cpk}$ ): Six sigma study guide articles.2014. Available at: https://sixsigmastudyguide.com/process-capability-cpcpk.Accessed on Aug 6, 2020.

24. Steiner S, Abraham B, MacKay J," Understanding process capability indices" International Conference on Production Research, Department of statistics and Actuarial Science, University of Waterloo.

25. Bissel AF, "How Reliable Is Your Capability Index?", Journal of Applied Statistics, 1990; 39:331-340.

26. Mcneese B, Cpk Vs. Ppk: Who Wins?: SPC for excel. 2014. Available

https://www.spcforexcel.com/knowledge/processcapability/cpk-vs-ppk-who-wins. Accessed on Aug 1, 2020

27. Gabriele A, Stefano N, "A Review of the Fundamentals on Process Capability, Process Performance, and Process Sigma, and an Introduction to Process Sigma Split", International Journal of Applied Engineering Research, 2017; 12(14):45564570 .

28. Ullman DG. "Robust decision making for engineering Design", J. of Engineering Design, 2001; 19(1):3-13.

29. Gebresenbet T, Jain PK, Jain SC, "Preliminary manufacturability analysis using feature-function resource considerations for cylindrical machined parts", Int. J. Computer Integrated Manufacturing, 2002; 15:361-378.

30. Bargellis A, "Design for process capability and capacity at the product conception stage" International Conference on Production Research, Department of Manufacturing Technologies, Kaunas University of Technology. 